Article

\title{
Quantification of the Morphological Signature of Roping Based on Multiscale Analysis and Autocorrelation Function Description
}

\author{
Julie Marteau $^{1, *(1)}$, Raphaël Deltombe ${ }^{2}$ and Maxence Bigerelle ${ }^{2}(\mathbb{D}$ \\ 1 Laboratoire Roberval FRE-CNRS, Centre de Recherches de Royallieu, Sorbonne Université, \\ Université de Technologie de Compiègne, CS 60319, 60203 Compiègne Cedex, France \\ 2 Laboratoire d'Automatique, de Mécanique et d'Informatique industrielle et Humaine (LAMIH) UMR-CNRS \\ 8201, Université Polytechnique Hauts de France, Le Mont Houy, 59313 Valenciennes, France; \\ raphael.deltombe@uphf.fr (R.D.) maxence.bigerelle@uphf.fr (M.B.) \\ * Correspondence: julie.marteau@utc.fr; Tel.: +33 3442-34603
}

Received: 26 May 2020; Accepted: 4 July 2020; Published: 7 July 2020

\begin{abstract}
Roping or ridging is a visual defect affecting the surface of ferritic stainless steels, assessed using visual inspection of the surfaces. The aim of this study was to quantify the morphological signature of roping to link roughness results with five levels of roping identified with visual inspection. First, the multiscale analysis of roughness showed that the texture aspect ratio $S_{\text {tr }}$ computed with a low-pass filter of $32 \mu \mathrm{m}$ gave a clear separation between the acceptable levels of roping and the non-acceptable levels (rejected sheets). To obtain a gradation description of roping instead of a binary description, a methodology based on the use of the autocorrelation function was created. It consisted of several steps: a low-pass filtering of the autocorrelation function at $150 \mu \mathrm{m}$, the segmentation of the autocorrelation into four stabilized portions, and finally, the computation of isotropy and the root-mean-square roughness $S_{q}$ on the obtained quarters of function. The use of the isotropy combined with the root-mean-square roughness $S_{q}$ led to a clear separation of the five levels of roping: the acceptable levels of roping corresponded to strong isotropy (values larger than $10 \%$ ) coupled with low root-mean-square roughness $\mathrm{S}_{\mathrm{q}}$. Both methodologies can be used to quantitatively describe surface morphology of roping in order to improve our understanding of the roping phenomenon.
\end{abstract}

Keywords: roping; ridging; topography; autocorrelation function; roughness

\section{Introduction}

Roping or ridging is a visual defect appearing on the surface of defect-free material sheets after drawing or stretching operations. The terms 'roping' and 'ridging' refer to the surface appearance of the material that shows rope-like features parallel to the prior rolling direction and distributed along the transverse direction. This phenomenon was observed in ferritic stainless steels $[1,2]$ as well as aluminum alloys [3,4]. Both materials are often used for exterior applications whose surface appearance is important (e.g., automotive body applications). There is thus a clear need for an objective method for the quantification of roping level. In the literature, roping quantification can be used:

- To assess the differences of predictions made by different models. Wu et al. [5] used a finite element method incorporating measured Electron Back Scattered Diffraction (EBSD) data to simulate the development of roping. They analyzed the changes in the surface profiles to compare different predictions.

- To measure the influence of grain size and shape on roping level. Patra et al. [6] examined the microstructure changes at different steps of the industrial process of $409 \mathrm{~L}$ grade ferritic stainless steel and identified a direct correlation between roping and the severity of coarse-grain banding. 
- To assess the influence of iron contents on roping phenomenon, Jin and Lloyd [7] investigated the impact of Fe contents on roping. In their study, the examined the evolution of roughness through the use of the arithmetical mean height $R_{a}$ and total height of the profile $R_{t}$ but they did not link the roping level (qualitative estimation of roping) with the roughness results.

Different comparison strategies were used to try to assess roping magnitude. As an example, Shi et al. [8] developed a three-dimensional crystal plasticity model based on finite elements to simulate sheet surface roughening after different tensile strain levels. In particular, they assessed the role of the banding of Cube and Goss texture components on roping in AA6111 sheets by examining the roughness profiles given by their model. Engler et al. [9] also used a qualitative description of the roughness profiles obtained with their visco-plastic self-consistent model to discuss the predictive ability of their model. In other studies, the total roping or ridging height is preferred to quantitatively compare roping magnitude. Ma et al. [10] used the ridging height (among other results) to assess the effects of rolling routes on roping magnitude. Shin et al. [11] also used the ridging height to quantify differences of roping between two stainless steel sheets. More recently, Lee et al. [12] used the ridging height to examine the relationship between grain size and ridging for ferritic stainless steel (as-cast and cold-rolled). Other researchers compared roping levels by using standard parameters such as the average surface roughness $R_{a}([13-16])$, the root-mean-square amplitude $R_{q}([17])$, the maximum profile peak height $R_{p}$ ([14]) or the peak-to-valley roughness ([13]). Lefebvre et al. [17] also computed the Fourier transform of the average two-dimensional roughness profile to identify characteristic wavelengths for roping. Choi et al. [18] preferred to introduce a modified roughness parameter defined as the difference between average heights of the upper $\mathrm{N} \%$ of peaks and the lower $\mathrm{N} \%$ of valleys to quantify the degree of surface roughness. They concluded that this parameter was more relevant for the description of roping than the use of $R_{\mathrm{q}}$. Guillotin et al. [19] computed a roping grade based on the results of the areal power spectral density. They found good agreement with the roping level obtained with visual assessment. However, these computations were made on 'stoned' surfaces. The stoning technique artificially increases the contrast between valleys and peaks by first ink-blackening the surface and then manually grinding it with an abrasive paper.

Thus, many strategies were used to describe the surface topography induced by roping. However, as underlined by Stoudt and Hubbard [20], methods used to interpret roughness data (chosen parameter, use of profiles, etc.) may be sources of error of interpretation.

The aim of this paper is to quantify the morphological signature of roping to understand the link between the surface morphology and the roping levels determined with visual inspection of the surfaces. To do so, a multiscale analysis based on an expert system assessing the best scale and roughness parameter [21] was first used to link a standard roughness parameter at a given scale with the roping levels. Then, a new methodology based on a quantitative description of the autocorrelation function was proposed.

\section{Materials and Methods}

\subsection{Material and Roughness Measurements}

Eleven sheets of cold-rolled AISI 445 ferritic stainless steel (20.20\%Cr, Aperam, Isbergues, France) were used for this study. Five roping levels were determined by the manufacturer's visual assessment. This visual assessment is based on the recommendations of the quality department established with customer satisfaction. Among these five levels, the first two levels (hereafter called Level 1 and 2) were considered as acceptable while the three other levels (Level 3, 4 and 5) were considered as non-acceptable. The number of cold-rolled sheets per roping level is given in Table 1. 
Table 1. Number of cold-rolled sheets per roping level.

\begin{tabular}{ccccc}
\hline Level 1 & Level 2 & Level 3 & Level 4 & Level 5 \\
\hline 2 & 2 & 3 & 3 & 1 \\
\hline
\end{tabular}

The topography of the specimens was measured using a white-light interferometer (Zygo NewView ${ }^{\mathrm{TM}} 7300$, Zygo Corp, Middlefield, CT, USA). Roughness measurements were performed before and after $15 \%$ tensile tests in the rolling direction. The value of $15 \%$ was chosen to match previous works on roping $[13,22,23]$. Tensile tests were performed at room temperature at a strain rate of $10^{-3} \mathrm{~s}^{-1}$ with large tensile test samples ( $250 \mathrm{~mm}$ gauge length by $50 \mathrm{~mm}$ gauge width), made from $1.4 \mathrm{~mm}$ thick sheets.

Depending on the conducted analysis, different measurement conditions were chosen:

- $\quad$ for the multiscale analysis, 100 measurements of $1188 \mu \mathrm{m} \times 891 \mu \mathrm{m}$ with a step of $1.09 \mu \mathrm{m}$ were performed on each specimen with a 20× objective (I 200646, Zygo Corp, Middlefield, CT, USA). An example of measurement is shown in Figure 1.

- for the autocorrelation function description, two very large measurements of $84,385 \mu \mathrm{m} \times$ $17,691 \mu \mathrm{m}$ were performed on each specimen with a $5 \times$ objective (CF Plan 427028 , Nikon, Tokyo, Japan) (and 0.5× zoom).
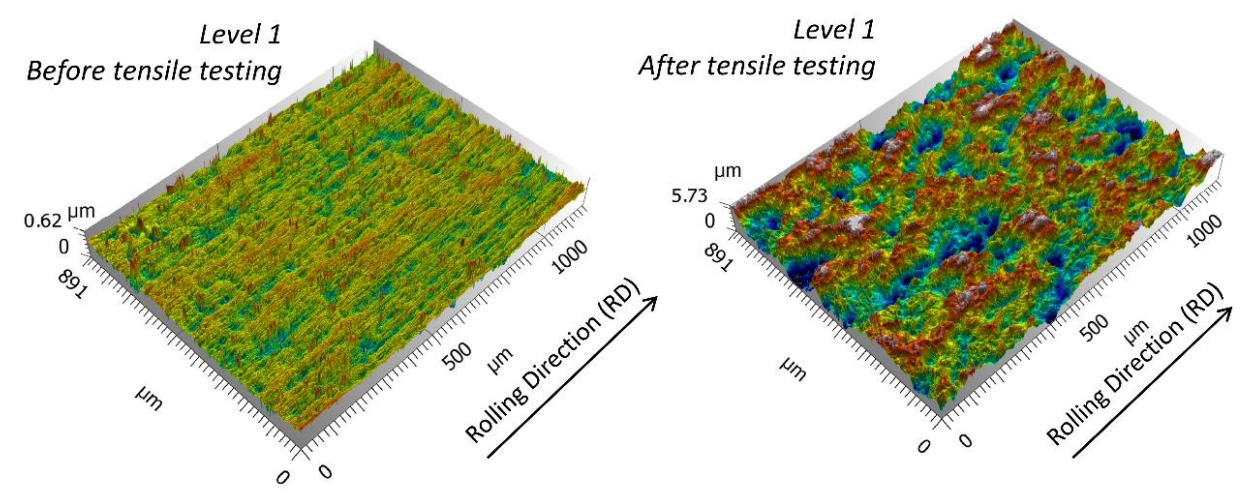

Level 5

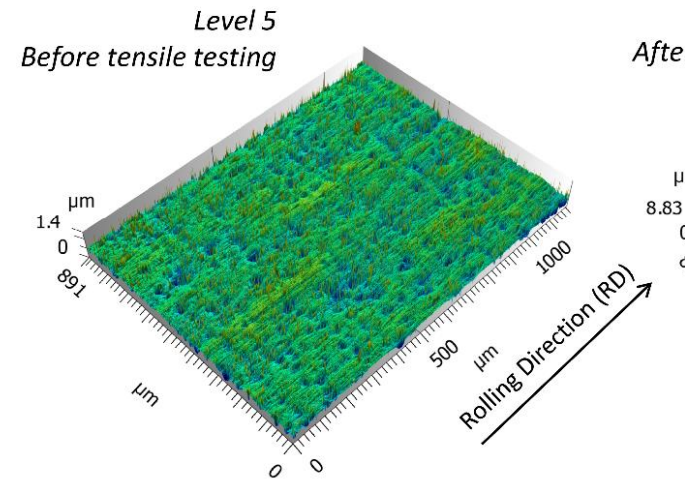

Level 5

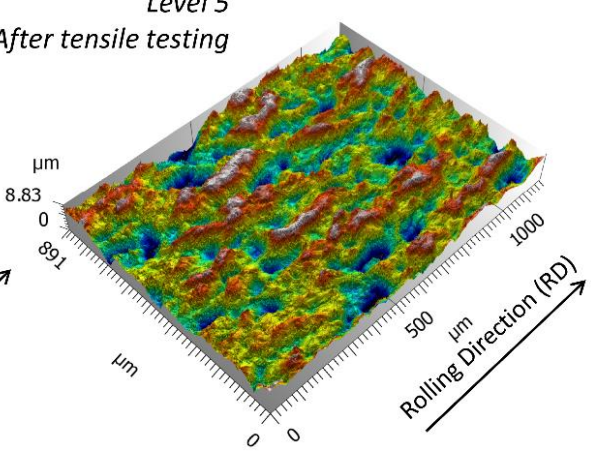

Figure 1. Examples of topography measurements of $1188 \mu \mathrm{m} \times 891 \mu \mathrm{m}$ for roping classified as Level 1 and Level 5 , before and after tensile testing.

It should be underlined that the very large measurements $(84,385 \mu \mathrm{m} \times 17,691 \mu \mathrm{m})$ were first used in a preliminary study to assess the capability of detecting roping. Based on these first observations, it was decided to use measurements of lower dimensions $(1188 \mu \mathrm{m} \times 891 \mu \mathrm{m})$ that covered more randomly the surface, with higher accuracy but with a similar total measurement area. 


\subsection{Multiscale Analysis Methodology}

The multiscale analysis was performed using three types of robust Gaussian filters [24]: a low-pass, a high-pass and a band-pass filter (on the $1188 \mu \mathrm{m} \times 891 \mu \mathrm{m}$ measurements). The following eighteen cut-off lengths were used: 8, 9, 11, 14, 17, 20, 25, 31, 38, 48, 59, 74, 99, 132, 170, 238, 396 and $594 \mu \mathrm{m}$. This choice was based on a geometric progression. For the band-pass filter, the indicated cut-off length corresponds to the first cut-off of the filter. The cut-off bandwidth is obtained by subtracting the latter value by the next larger cut-off length of the list. As an example, 'Band-pass filter, $17 \mu \mathrm{m}$ ' means that the first cut-off is equal to $17 \mu \mathrm{m}$ and that the bandwidth is equal to $(20-17)=3 \mu \mathrm{m}$. Following this decomposition of the topography, fifty roughness parameters $[25,26]$ were assessed. These parameters are: height parameters (arithmetical mean height $S_{a}$, root-mean-square roughness $S_{q}$, kurtosis $S_{k u}$, etc.), functional parameters (areal material ratio $S_{m r}$, etc.), spatial parameters (autocorrelation length $S_{\mathrm{al}}$, texture aspect ratio $S_{\mathrm{tr}}$, texture direction $S_{\mathrm{td}}$, etc.), hybrid parameters (root-mean-square gradient $\mathrm{S}_{\mathrm{dq}}$, etc.), functional volume parameters, feature parameters, etc.

\section{Results and Discussion}

\subsection{Multiscale Analysis}

In this section, the results will be based on the measurements having an area equal to $1188 \mu \mathrm{m}$ $\times 891 \mu \mathrm{m}$. As previously introduced, visual inspection of the AISI 445 ferritic stainless steel sheets enabled the manufacturer to classify the sheets into five roping levels, after the tensile tests: Level 1 and 2 were acceptable whereas Level 3, 4 and 5 were not acceptable. These different classifications (by levels or by acceptability) led to test two kinds of correlation:

(i) a correlation between a tested roughness parameter and the five levels of roping, hereafter called 'gradation description',

(ii) a correlation between a roughness parameter values and the acceptable or non-acceptable status of the specimens, hereafter called 'binary description'.

These correlations were made using different types of relationships combining linear and logarithmic parts and the best relationship was chosen as the one giving the highest coefficient of determination.

As the arithmetical mean height is often used to quantify roping level, this roughness parameter was computed for all the specimens. Figure 2a shows the $S_{a}$ values computed for the five identified levels of roping. These $S_{a}$ values were computed at full scale, i.e., no filtering was performed on the measured surfaces. The $S_{a}$ value found for Level 1 is significantly lower than the $S_{a}$ values computed for the other levels: $0.95 \mu \mathrm{m}$ for Level 1 while the other levels have values comprised between $1.12 \mu \mathrm{m}$ and $1.32 \mu \mathrm{m}$. However, these differences do not correspond to the manufacturer's categories: Level 1 and Level 2 are considered acceptable, but they have very different $S_{a}$ values (corresponding to the extrema of the curves). There is no correlation between the $S_{a}$ parameter and the roping levels defined by the manufacturer. This result is in agreement with the literature: Baczynski et al. [13], who investigated roping in aluminum automotive alloy, found no correlation between height roughness parameters and the visual levels of roping. Similarly, Guillotin et al. [19] found that the height magnitude of the topography was not the most important surface feature for characterizing roping level in aluminum sheets.

Then, the $S_{a}$ parameter was computed using the multiscale decomposition of the surfaces i.e., it was calculated for all the filtered surfaces listed in Section 2.1. Figure $2 \mathrm{~b}$ shows the best correlation obtained for a binary description. It was obtained using a low-pass filter and a cut-off length of $200 \mu \mathrm{m}$. Again, there is no clear correlation between the roping levels and the $S_{a}$ values, even when computed at the most relevant scale. 

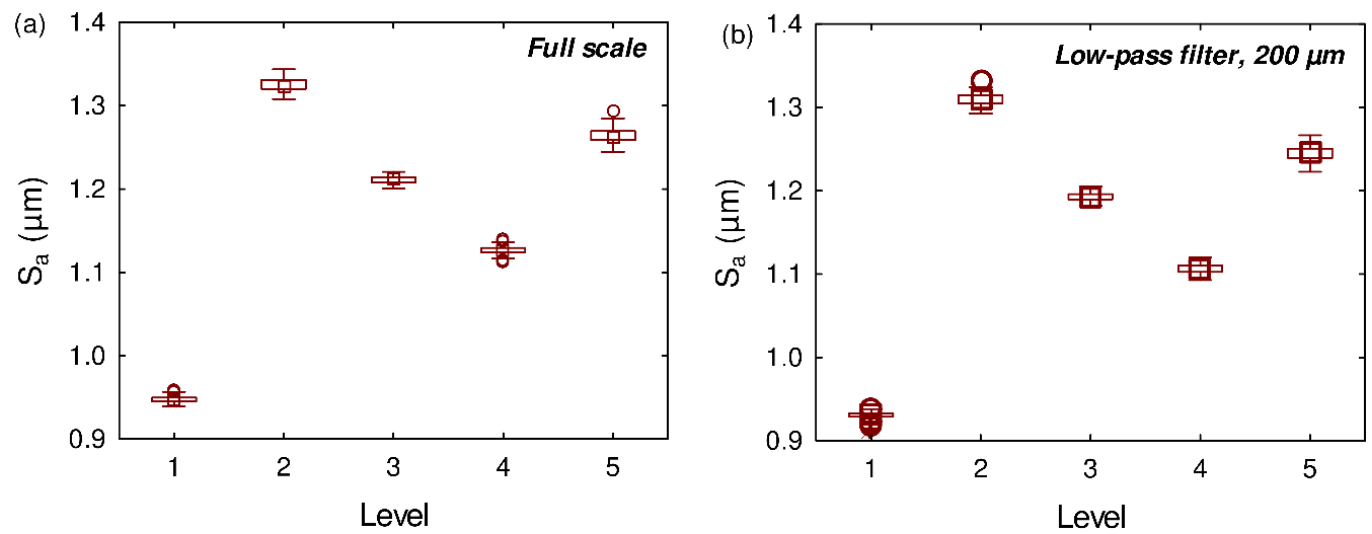

Figure 2. (a) Full scale arithmetical mean height $S_{a}$ values as a function of the visual roping levels, after tensile testing, (b) Arithmetical mean height $S_{a}$ values obtained with a low-pass filter and a cut-off of $200 \mu \mathrm{m}$ as a function of the visual roping levels, after tensile testing.

The multiscale analysis was then performed using a total of fifty roughness parameters to determine which combination of parameter and scale led to the best level gradation description and to the best binary description of roping. As shown in Figure 3, the best level gradation description was obtained with the bearing index $S_{\text {bi }}$ using a band-pass filter with a cut-off of $20 \mu \mathrm{m}$ and a bandwidth of $5 \mu \mathrm{m}$. The bearing index $\mathrm{S}_{\mathrm{bi}}$ is a functional index defined as the ratio between the root-mean-square parameter $S_{q}$ and the height at $5 \%$ of the bearing surface. Figure 3 shows that there is a gradual increase of the $S_{b i}$ values with the level of roping. However, the median values for all the levels are comprised between 0.45 and 0.48 while the minimum and maximum values are comprised between 0.44 and 0.47 , respectively. Thus, the $S_{b i}$ values are globally low with a similar order of magnitude (difference of $7 \%$ between the extrema).

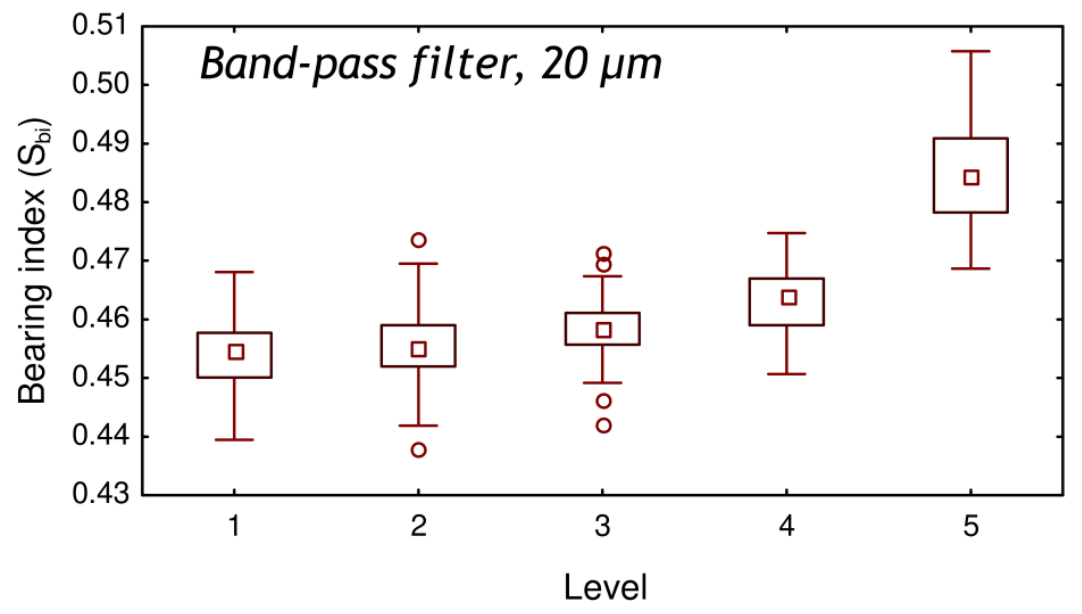

Figure 3. Bearing index $S_{b i}$ values obtained with a band-pass filter with a cut-off of $20 \mu \mathrm{m}$ and a bandwidth of $5 \mu \mathrm{m}$ as a function of the visual roping levels, after tensile testing.

Figure 4 shows the best correlation achieved for the binary description of roping: the best combination is obtained with the texture aspect ratio $S_{\text {tr }}$ calculated with a low-pass filter and a cut-off length of $32 \mu \mathrm{m}$. As observed in Figure 4, there is a clear separation of data: a stronger anisotropy of the autocorrelation function is obtained for the rejected specimens (Level 3 to 5) than for the accepted specimens (Level 1 to 2). According to the previous results, the roping level was not relevantly described by the roughness amplitude but seems to be well described by the oriented and periodical organization of the ropes. This result is in agreement with Guillotin et al. [19] who found that the 
morphological distribution of surface features was more important than height magnitude to link topography with roping levels in aluminum alloys.

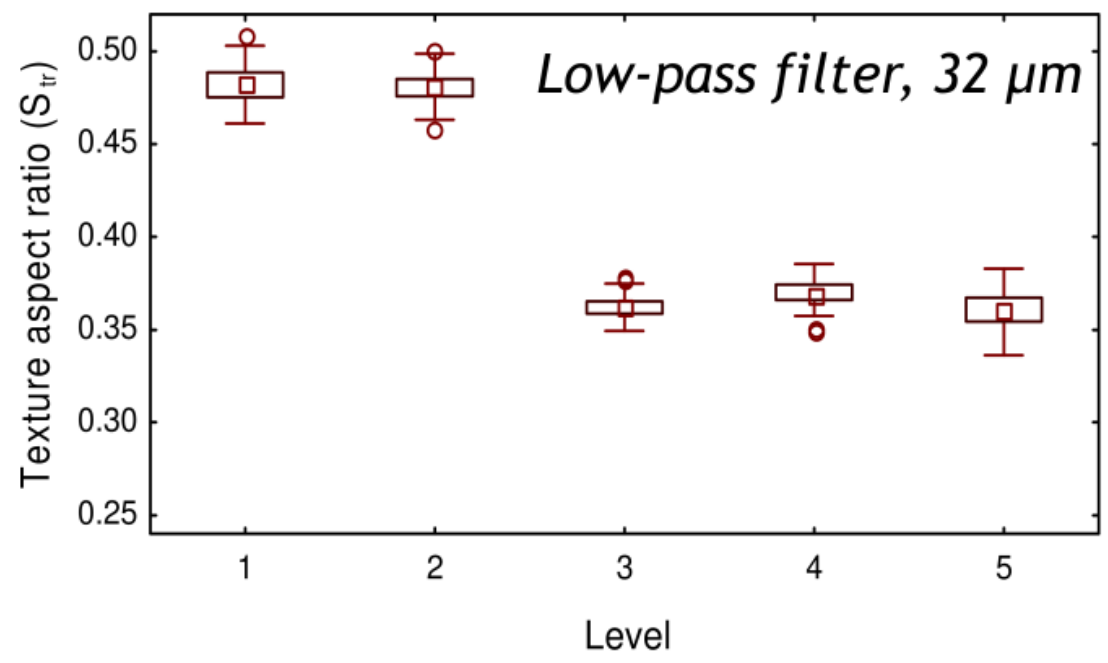

Figure 4. Texture aspect ratio $S_{\text {tr }}$ values obtained with a low-pass filter of $32 \mu \mathrm{m}$ as a function of the visual roping levels after tensile testing.

\subsection{Description based on the Autocorrelation Function}

Figure 4 showed us that computations based on the autocorrelation function (i.e., the parameter $S_{\text {tr }}$ ) are promising to establish a relationship between the visual level of roping after tensile testing and the morphology signature of roping. However, to get robust results from the use of the autocorrelation function, large measurement areas are required. This is why the $84,384 \mu \mathrm{m} \times 17,691 \mu \mathrm{m}$ measurements will be used in the following sections. High-pass filtering was performed on these measurements at $25,000 \mu \mathrm{m}$ to remove waviness caused by tensile testing.

\subsubsection{Regularity Parameter}

According to the previous results, a certain regularity or order seems to be characteristic of the morphology of the roping phenomenon. Fourier analysis tends to be inadequate for the description of the regularity or order of a surface. This is why Guillemot et al. [27] created a non-standardized 'regularity' parameter. This parameter is based on a normalized autocorrelation function expressed in polar coordinates $(R, \theta)$ :

$$
S_{\text {reg }}(\theta, \lambda)=100 \frac{\sum_{k=1}^{k_{\max }(\theta, \lambda)}\left|\int_{k \cdot L(\theta, \lambda)}^{(k+1) \cdot L(\theta, \lambda)} A C F(R, \theta) d R\right|}{k_{\max } \int_{0}^{L(\theta, \lambda)} A C F(R, \theta) d R}
$$

where $\lambda$ is the inverse lag length, $L$ is the autocorrelation length and $k_{\max }$ the maximum value of index $k$ in any $\theta$ direction.

This parameter is equal to $0 \%$ for uncorrelated random surfaces whereas it will be equal to $100 \%$ for perfect periodic surfaces having no noise. To give relevant results, the autocorrelation function needs to be computed at the appropriate threshold. To find this threshold, the texture aspect ratio $\mathrm{S}_{\mathrm{tr}}$ was computed for all the threshold values, as displayed in Figure 5. The maximum anisotropy was found when using a threshold equal to 0.5 . This value was thus used for the computation of the regularity parameter $\mathrm{S}_{\text {reg. }}$. 


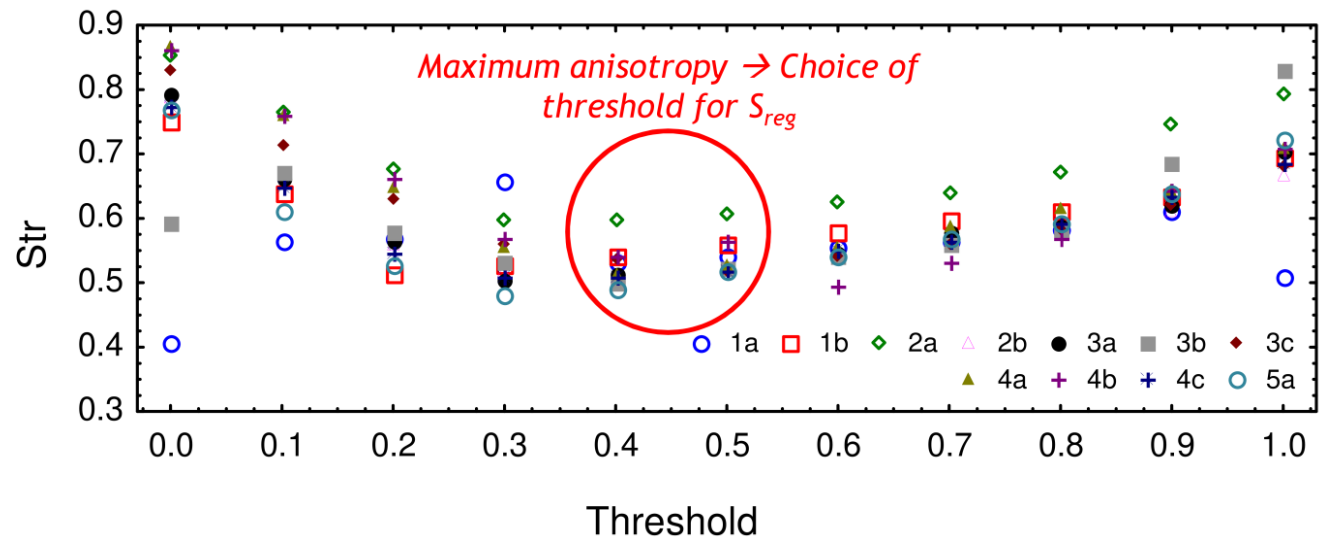

Figure 5. Texture aspect ratio $S_{\text {tr }}$ results as a function of the threshold value.

Figure 6 shows the results of the computation of the regularity parameter $S_{\text {reg }}$ in polar coordinates. It can be observed that for Level 1 and 2 (acceptable levels of roping), the $S_{\text {reg }}$ distribution tends to have a round shape. On the opposite, Level 3, 4 and 5 (rejected sheets) tends to develop a nose along the $\mathrm{X}$-direction. It should be noted that the regularity parameter $\mathrm{S}_{\text {reg }}$ is mathematically independent of amplitude. It thus confirms our first results: parameters describing the surface order are relevant for the quantification of the roping and more specifically to link topography with roping levels.

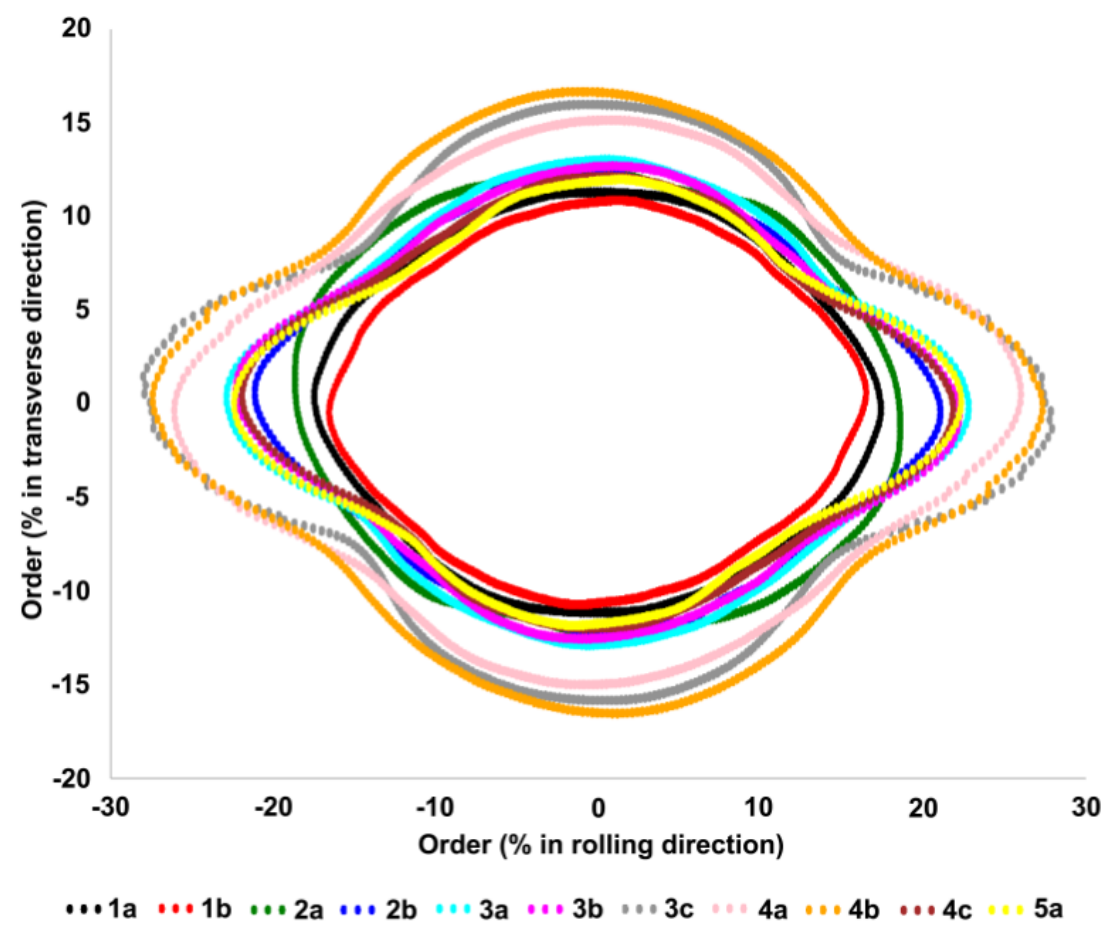

Figure 6. Representation of the regularity parameter $S_{\text {reg }}$ results for all the measured sheets in polar coordinates.

The regularity parameter $S_{\text {reg }}$ gave very relevant results. However, as it is not a standard roughness parameter, it may limit its use for roping description. This is why we developed another methodology based on standard functions and parameters. The next section is dedicated to the presentation of this methodology. 


\subsubsection{Quantitative Description of Roping based on the Autocorrelation Function}

First, the relevant scale for the computation of the autocorrelation function should be determined. To do so, the autocorrelation length $S_{a l}$ is plotted as a function of threshold, as represented in Figure 7. On the latter, it can be seen that for a threshold equal to 0.5 , the autocorrelation length $S_{\text {al }}$ is equal to $300 \mu \mathrm{m}$. As a consequence, the roping phenomenon in this study should be investigated at a scale of $300 \mu \mathrm{m}$. However, to avoid any cut-off artefacts, a low-pass filtering at $150 \mu \mathrm{m}$ will be used hereafter.

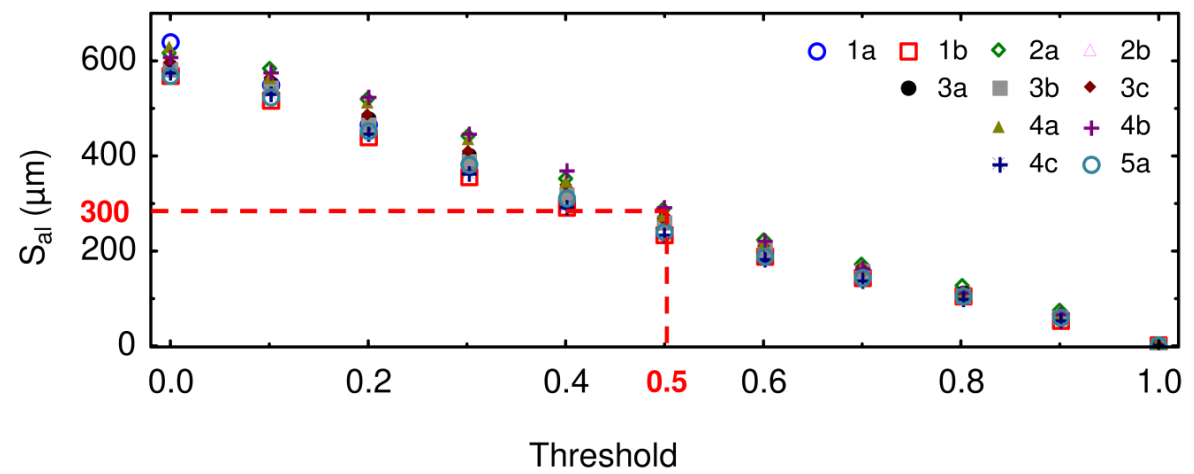

Figure 7. Autocorrelation length $S_{\mathrm{al}}$ as a function of the threshold.

The autocorrelation function was then computed on the surface filtered at the appropriate scale. This computed autocorrelation function was then divided into four 'stabilized' quarters (i.e., excluding the central peak), as depicted in Figure 8. The anisotropy of each quarter was then enhanced using a $3 \times 3$ gradient filter.

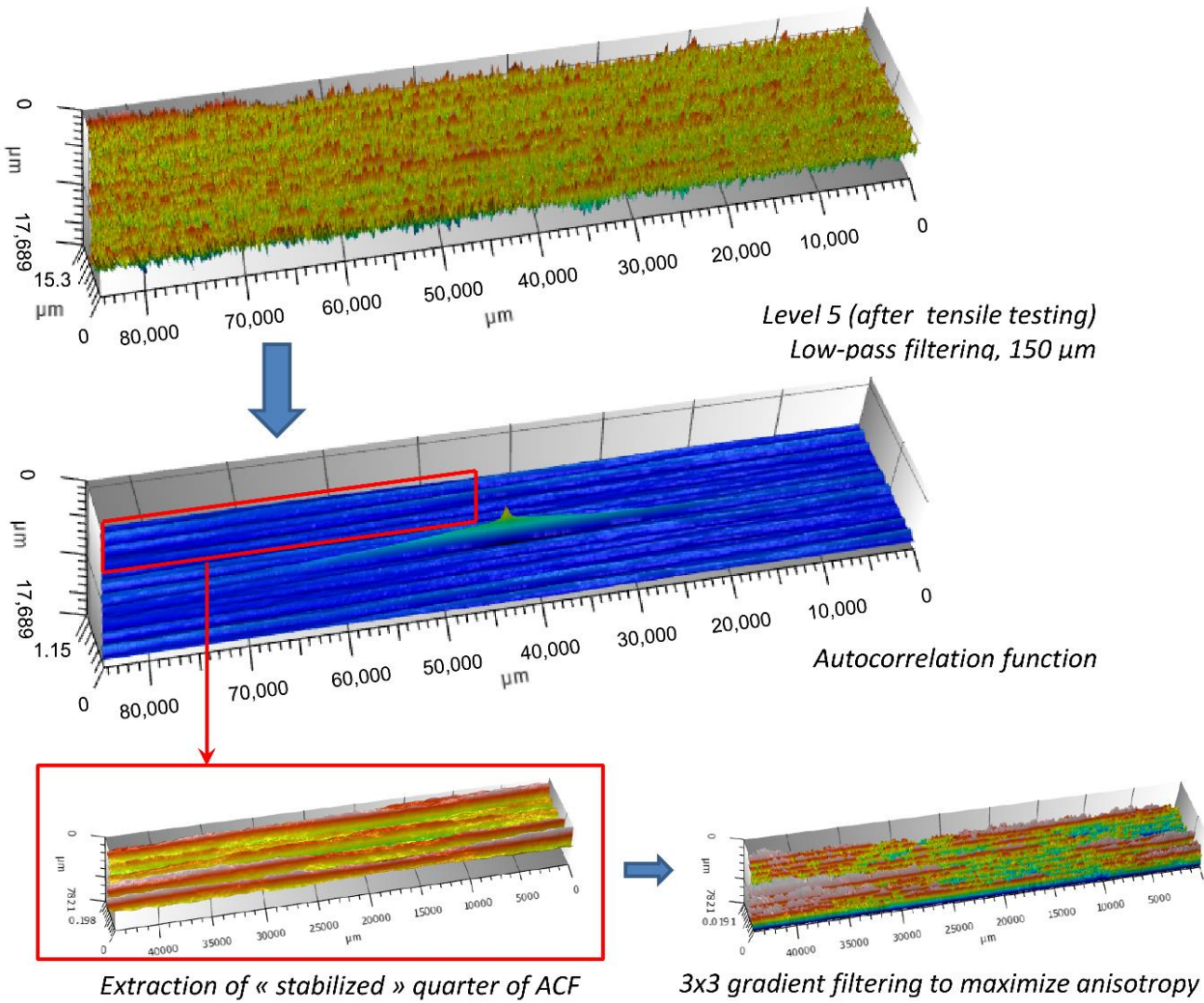

Figure 8. Methodology of extraction of quarters of autocorrelation functions. 
Examples of the topography of the quarters of the autocorrelation functions are shown in Figure 9, for all the roping levels. A quick look at the difference of topographies between the levels show that this methodology is promising; clear differences appear between the accepted and rejected sheets. To obtain a quantitative description of these results, height roughness parameters as well as isotropy were computed on the extracted quarters of the autocorrelation function.

The parameters enabling the best binary description of roping were then searched using the same method as the one described in Section 3.1. It was found that the isotropy and the root-mean-square roughness $S_{q}$ gave the best binary description. Figure 10 shows the mean value obtained with the four corners for each $84,385 \mu \mathrm{m} \times 17,691 \mu \mathrm{m}$ measurement. A clear separation of roping levels can be observed in Figure 10 between the acceptable sheets and the rejected sheets. Large isotropy values (larger than 10\%) will guarantee the manufacturer a lack of roping effect on the produced sheets. The combined use of the isotropy and the $\mathrm{S}_{\mathrm{q}}$ parameter led to a gradation of the roping response: acceptable levels have low amplitudes as well as large isotropy values while unacceptable levels have larger amplitudes with low isotropy values.
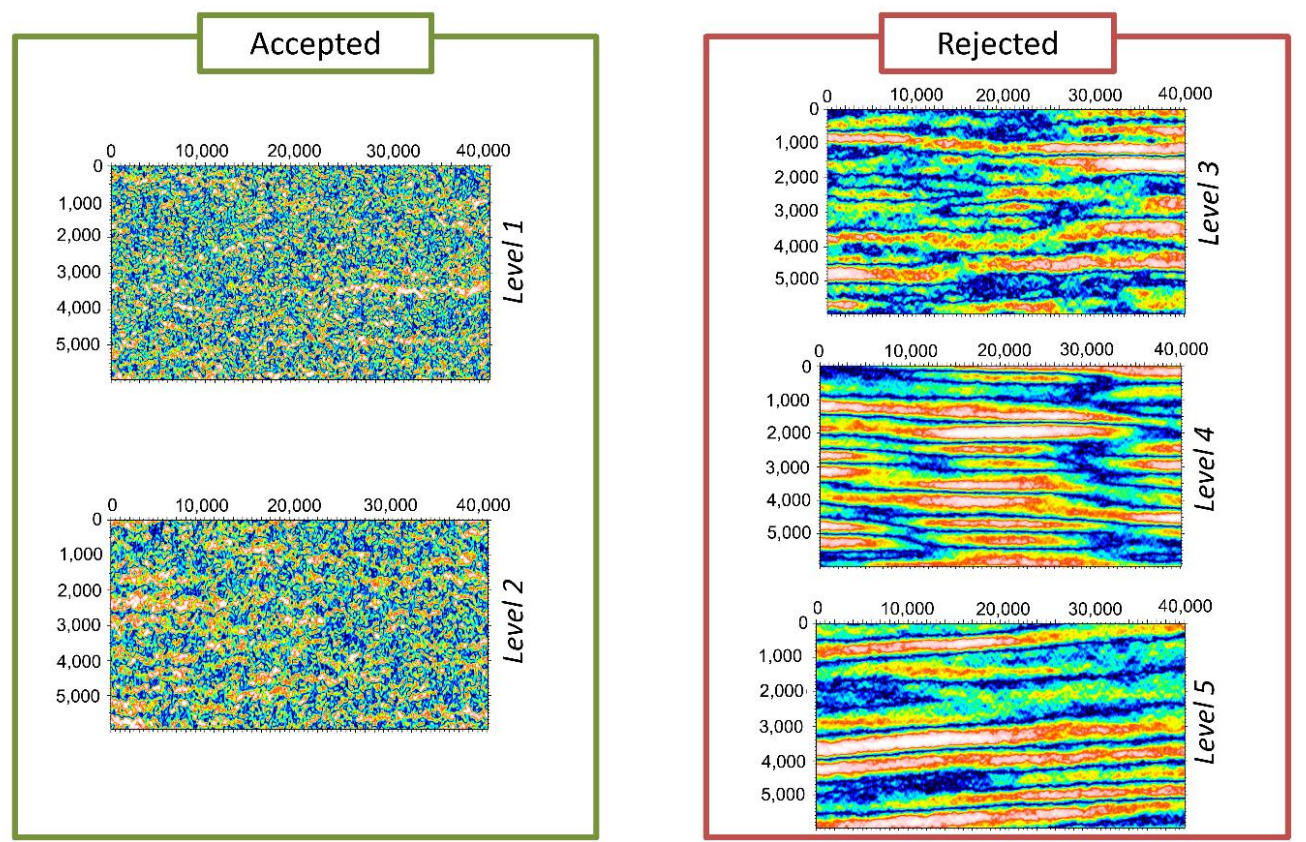

Figure 9. Topography of the autocorrelation function quarters for the five levels of roping (the $X$ and $Y$ axis units are micrometers).

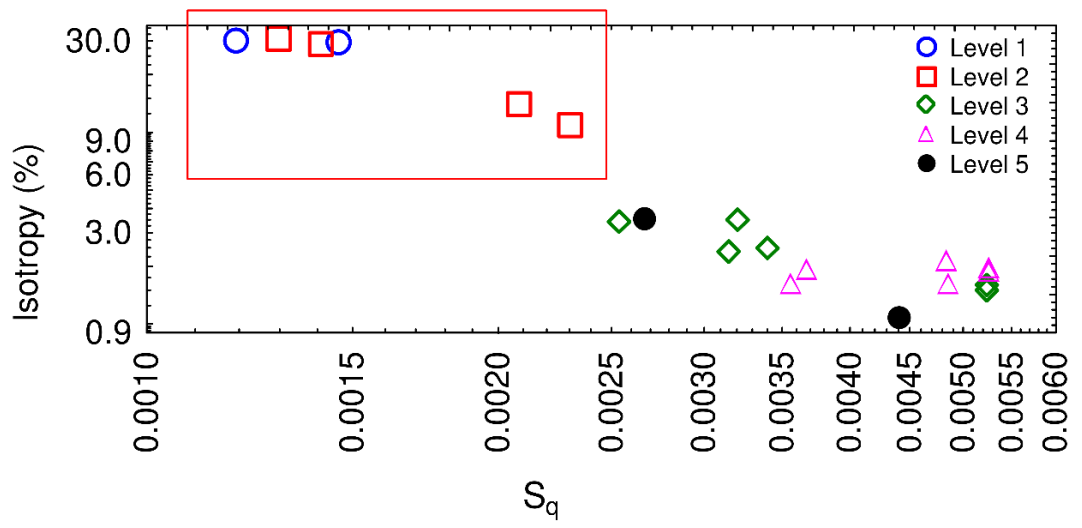

Figure 10. Isotropy as a function of the root-mean-square roughness $S_{q}$ computed for all the quarters of autocorrelation function. 


\section{Conclusions}

In this work, two main methods were tested to quantify the morphological signature of roping and to link roughness results with the five levels of roping identified with visual inspection.

The first method was based on the use of multiscale analysis to determine the best parameter and scale for the description of roping levels. It was found that the texture aspect ratio $S_{\text {tr }}$ computed with a low-pass filter and a cut-off length of $32 \mu \mathrm{m}$ gave the best binary description: clear separation was obtained between the acceptable levels of roping and the non-acceptable levels. The identified scale may be comparable to the grain sizes (or the sizes of the clusters of grains sharing similar orientations) but further work is required to check this hypothesis. This first method gave interesting results as it enabled the relevant scale of the signal to be identified. Furthermore, it underlined the relevance of the autocorrelation function for the description of the roping phenomenon, through the identification of the $S_{\text {tr }}$ parameter.

The second method was based on the use of the autocorrelation function for the quantification of roping. First, the regularity parameter $S_{\text {reg }}$ was computed and gave a good detection of roping. However, as this parameter is not standard, its use may be limited. This is a methodology based the description of the autocorrelation function was proposed. First, the relevant scale of the analysis was determined to be $150 \mu \mathrm{m}$ for this study. After a low-pass filtering, the autocorrelation function was computed and then segmented into four stabilized portions. Different heights parameters and isotropy parameters were computed on these quarters to determine the best quantitative descriptors of roping. It was found that the isotropy combined with the root-mean-square roughness $\mathrm{S}_{\mathrm{q}}$ gave a good description of the roping levels. Large isotropy values (larger than 10\%) will guarantee the manufacturer a lack of roping effect on produced sheets. Both methodologies can be used to quantitatively describe surface morphology of roping in order to improve our understanding of the roping phenomenon.

Author Contributions: Conceptualization, M.B. and J.M.; methodology, M.B., R.D. and J.M.; software: M.B.; validation, M.B., J.M. and R.D.; formal analysis, M.B.; writing—original draft preparation, J.M.; writing一review and editing, J.M. and M.B.; administration, M.B.; funding acquisition, M.B. All authors have read and agreed to the published version of the manuscript.

Funding: This research received no external funding.

Conflicts of Interest: The authors declare no conflict of interest.

\section{References}

1. Sinclair, C.W. Embedded Grain Rotation and Roping of Stainless Steel. Metall. Mater. Trans. A 2007, 38, 2435-2441. [CrossRef]

2. Ma, X.; Zhao, J.; Du, W.; Zhang, X.; Jiang, L.; Jiang, Z. Quantification of texture-induced ridging in ferritic stainless steels 430 and 430LR during tensile deformation. J. Mater. Res. Technol. 2019, 8, $2041-2051$. [CrossRef]

3. Kusters, S.; Seefeldt, M.; Van Houtte, P. A Fourier image analysis technique to quantify the banding behavior of surface texture components in AA6xxx aluminum sheet. Mater. Sci. Eng. A 2010, 527, 6239-6243. [CrossRef]

4. Qin, L.; Seefeldt, M.; Van Houtte, P. Analysis of roping of aluminum sheet materials based on the meso-scale moving window approach. Acta Mater. 2015, 84, 215-228. [CrossRef]

5. Wu, P.D.; Lloyd, D.J.; Bosland, A.; Jin, H.; MacEwen, S.R. Analysis of roping in AA6111 automotive sheet. Acta Mater. 2003, 51, 1945-1957. [CrossRef]

6. Patra, S.; Ghosh, A.; Sood, J.; Singhal, L.K.; Podder, A.S.; Chakrabarti, D. Effect of coarse grain band on the ridging severity of 409L ferritic stainless steel. Mater. Des. 2016, 106, 336-348. [CrossRef]

7. Jin, H.; Lloyd, D.J. Roping in 6111 aluminum alloys with various iron contents. Mater. Sci. Eng. A 2005, 403, 112-119. [CrossRef]

8. Shi, Y.; Jin, H.; Wu, P.D.; Lloyd, D.J. Analysis of roping in an AA6111 T4P automotive sheet in 3D deformation states. Acta Mater. 2017, 124, 598-607. [CrossRef] 
9. Engler, O.; Schäfer, C.; Brinkman, H.J. Crystal-plasticity simulation of the correlation of microtexture and roping in AA 6xxx Al-Mg-Si sheet alloys for automotive applications. Acta Mater. 2012, 60, 5217-5232. [CrossRef]

10. Shin, H.-J.; An, J.-K.; Park, S.H.; Lee, D.N. The effect of texture on ridging of ferritic stainless steel. Acta Mater. 2003, 51, 4693-4706. [CrossRef]

11. Ma, X.; Zhao, J.; Du, W.; Zhang, X.; Jiang, Z. Effects of rolling processes on ridging generation of ferritic stainless steel. Mater. Charact. 2018, 137, 201-211. [CrossRef]

12. Lee, M.H.; Kim, R.; Park, J.H. Effect of nitrogen on grain growth and formability of Ti-stabilized ferritic stainless steels. Sci. Rep. 2019, 9, 1-11. [CrossRef] [PubMed]

13. Baczynski, G.J.; Guzzo, R.; Ball, M.D.; Lloyd, D.J. Development of roping in an aluminum automotive alloy AA6111. Acta Mater. 2000, 48, 3361-3376. [CrossRef]

14. Zhang, C.; Liu, Z.; Wang, G. Effects of hot rolled shear bands on formability and surface ridging of an ultra purified 21\%Cr ferritic stainless steel. J. Mater. Process. Technol. 2011, 211, 1051-1059. [CrossRef]

15. Cai, Y.; Wang, X.; Yuan, S. Analysis of surface roughening behavior of 6063 aluminum alloy by tensile testing of a trapezoidal uniaxial specimen. Mater. Sci. Eng. A 2016, 672, 184-193. [CrossRef]

16. Cai, Y.; Wang, X.; Yuan, S. Surface Roughening Behavior of 6063 Aluminum Alloy during Bulging by Spun Tubes. Materials (Basel). 2017, 10, 299. [CrossRef]

17. Lefebvre, G.; Sinclair, C.W.; Lebensohn, R.A.; Mithieux, J.-D. Accounting for local interactions in the prediction of roping of ferritic stainless steel sheets. Model. Simul. Mater. Sci. Eng. 2012, 20, 024008. [CrossRef]

18. Choi, Y.S.; Piehler, H.R.; Rollett, A.D. Introduction and application of modified surface roughness parameters based on the topographical distributions of peaks and valleys. Mater. Charact. 2007, 58, 901-908. [CrossRef]

19. Guillotin, A.; Guiglionda, G.; Maurice, C.; Driver, J.H. Quantification of roping intensity on aluminium sheets by Areal Power Spectral Density analysis. Mater. Charact. 2010, 61, 1119-1125. [CrossRef]

20. Stoudt, M.R.; Hubbard, J.B. Analysis of deformation-induced surface morphologies in steel sheet. Acta Mater. 2005, 53, 4293-4304. [CrossRef]

21. Bigerelle, M.; Najjar, D.; Mathia, T.; Iost, A.; Coorevits, T.; Anselme, K. An expert system to characterise the surfaces morphological properties according to their tribological functionalities: The relevance of a pair of roughness parameters. Tribol. Int. 2013, 59, 190-202. [CrossRef]

22. Takechi, H.; Kato, H.; Sunami, T.; Nakayama, T. The Mechanism of Ridging Formation in 17\%-Chromium Stainless Steel Sheets. Trans. Jap. Inst. Met. 1967, 8, 233-239. [CrossRef]

23. Wright, R.M. Anisotropic Plastic Flow in Ferritic stainless steels and the "roping" phenomenon. Met. Trans. 1972, 3, 83-91. [CrossRef]

24. ISO-ISO 16610-49:2015-Geometrical Product Specification (GPS) - Filtration-Part 49: Morphological Profile Filters: Scale Space Techniques. ISO: Geneva, Switzerland. Available online: https://www.iso.org/standard/61381 (accessed on 10 March 2020).

25. Stout, K.J.; Matthia, T.; Sullivan, P.J.; Dong, W.P.; Mainsah, E.; Luo, N.; Zahouani, H. The Developments of Methods for the Characterisation of Roughness in Three Dimensions; Office for Official Publications of the European Communities: Luxembourg, 1993.

26. ISO-ISO 25178-1:2016-Geometrical Product Specifications (GPS)-Surface Texture: Areal-Part 1: Indication of Surface Texture. ISO: Geneva, Switzerland. Available online: https://www.iso.org/standard/46065.html (accessed on 7 July 2020).

27. Guillemot, G.; Bigerelle, M.; Khawaja, Z. 3D parameter to quantify the anisotropy measurement of periodic structures on rough surfaces. Scanning 2014, 36, 127-133. [CrossRef]

(C) 2020 by the authors. Licensee MDPI, Basel, Switzerland. This article is an open access article distributed under the terms and conditions of the Creative Commons Attribution (CC BY) license (http://creativecommons.org/licenses/by/4.0/). 